\title{
Catálogo de obras de Traductología (2019-2021)
}

Alicia García Ferreras

Universidad de Málaga
Son numerosas las obras que se han incorporado recientemente al ya de por sí amplio catálogo de la teoría de la traducción. El listado que aquí se presenta, que recoge algunos de los títulos publicados entre los años 2019 y 2021, se manifiesta como un reflejo del panorama traductológico contemporáneo.

Con el fin de proporcionar un listado asequible, se ha realizado un cribado que atiende a los siguientes criterios: una vez consultados distintos recursos, como la Base de datos de libros publicados en España, Dialnet, Book Citation Index y MLA, se han recogido exclusivamente los títulos aparecidos entre los años 2019 y 2021. Posteriormente, se ha examinado cada uno de los volúmenes para delimitar los temas abordados con más asiduidad en el ámbito de la traducción actual. Finalmente, se han seleccionado varios tomos que tratan las distintas temáticas desde aproximaciones que proporcionan una visión innovadora sobre las cuestiones que parecen despertar un mayor interés entre los traductores. Esta selección se ha realizado atendiendo a la descripción que se ofrece en la ficha de cada libro. Cabe señalar que, a pesar de haber hallado un gran número de obras, se ha decidido incluir solo 53 para no obtener una lista demasiado extensa. Se han descartado, entre otros, algunos textos que ya se han reseñado en los dos últimos números de la revista TRANS. 
552 La división temática que se propone es meramente organizativa y muchos de los temas convergen, al igual que ocurre en la actividad traductora, interdisciplinar por naturaleza. No obstante, permite observar qué temas suscitan un mayor interés entre los investigadores; por ejemplo, son varias las obras que abordan aspectos relacionados con estudios poscoloniales y nuevas tecnologías y, a su vez, parece que la traducción especializada continúa generando un gran interés. Asimismo, se ponen de relieve aquellas parcelas que podrían investigarse en un futuro.

\section{TEORÍAS DE LA TRADUCCIÓN GENERAL}

\section{- Contra Instrumentalism: A Translation Polemic}

Autor: Lawrence Venuti

Editorial: University of Nebraska Press

Año: 2019

Páginas: $222 \mathrm{pp}$.

Este volumen pretende acabar con el instrumentalismo, un modelo imperante en traductología. El autor defiende que la traducción entraña un acto interpretativo y, por tanto, es necesario un modelo hermenéutico que ofrezca una comprensión más completa e incisiva de la disciplina traductora.

\section{Referencia}

Venuti, Lawrence (2019): Contra Instrumentalism: A Translation Polemic. Lincoln: University of Nebraska Press.

\section{- Las fronteras de la traducción: Las prácticas traductivas como cuestión sociocultural}

Autor: Mirko Lampis (ed.)

Editorial: Alfar

Año: 2019

Páginas: $222 \mathrm{pp}$.

Esta obra reúne ensayos que definen el mundo de la traducción «más allá de las primeras acep- ciones que ofrecen los diccionarios»; se examinan incluso los procesos de transformación semiótica, de apropiación de la alteridad, construcción identitaria y recreación, entre otros.

\section{Referencia}

LAMPIS, Mirko (ed.) (2019): Las fronteras de la traducción: Las prácticas traductivas como cuestión sociocultural, Sevilla: Alfar.

- Sense in Translation: Essays on the Bilingual Body

Autora: Caroline Rabourdin

Editorial: Routledge

Año: 2020

Páginas: 104 pp.

Esta obra recopila trabajos que exploran la compleja relación entre la traducción lingüística y la traducción espacial y defienden la comprensión de la traducción lingüística como un fenómeno corporizado. La perspectiva interdisciplinar que se adopta pone de manifiesto la necesidad de entender la práctica traductora como una actividad que no se limita a lo lingüístico o a lo espacial, sino que permite al cuerpo bilingüe sentir y proporcionar sentido.

\section{Referencia}

Rabourdin, Caroline (2020): Sense in Translation: Essays on the Bilingual Body, Londres: Routledge.

\section{- Prismatic Translation}

Autor: Matthew Reynolds

Editorial: Legenda Books

Año: 2019

Páginas: 396 pp.

Este volumen explora los modos prismáticos de traducción presentes en el antiguo Egipto, el Taiwán contemporáneo, la Hungría del siglo xx, la India y otros lugares. Asimismo, examina la escritura literaria experimental, la política del 
lenguaje, las prácticas académicas y las múltiples posibilidades de traducción originadas por los medios digitales. El autor también traza el reciente crecimiento de los modos prismáticos en la traducción literaria anglófona y en la literatura traslativa.

\section{Referencia}

Reynolds, Matthew (2019): Prismatic Translation, Oxford: Legenda Books.

\section{PERSPECTIVA HISTÓRICA}

- Lenguas entre dos fuegos: intérpretes en la guerra civil española (1936-1939)

Autor: Jesús Baigorri Jalón

Editorial: Comares

Año: 2019

Páginas: $232 \mathrm{pp}$.

Este volumen arroja luz sobre el papel que desempeñaron los intérpretes durante la Guerra Civil española y demuestra de qué manera su labor posibilitó la comunicación entre los participantes de distintos orígenes. Los resultados de la investigación pueden ser de utilidad para aspectos que se dan en el ámbito de la interpretación actual, por ejemplo, para comprender la demanda de intérpretes, así como los dilemas éticos que se le plantean al desarrollo de esta actividad en los conflictos internacionales.

\section{Referencia}

BAIGorri Jalón, Jesús (2019): Lenguas entre dos fuegos: intérpretes en la guerra civil española (1936-1939), Granada: Comares.

\section{- La traducción en Europa durante la Edad Media}

Autora: Elisa Borsari

Editorial: Cilengua

Año: 2019

Páginas: $326 \mathrm{pp}$.
Este libro es el primero de varios tomos que recopilan trabajos sobre la labor traductora llevada a cabo en Europa durante la Edad Media. El presente volumen viaja desde los comienzos del período hasta los inicios del Humanismo.

\section{Referencia}

BORSARI, Elisa (coord.) (2019): La traducción en Europa durante la Edad Media, La Rioja: Cilengua.

\section{- ¿Pasarán? Kommunikation im Spanischen} Bürgerkrieg. Interacting in the Spanish Civil War

Autoras: Julia Kölbl, Iryna Orlova y Michaela Wolf (eds.)

Editorial: new academic press

Año: 2020

Páginas: $224 \mathrm{pp}$.

Esta monografía realiza una aportación significativa a una cuestión que parece haber pasado desapercibida en la investigación traductológica: la comunicación que tuvo lugar entre los brigadistas internacionales durante la Guerra Civil española. El volumen parte del multilingüismo presente durante el conflicto para examinar las actividades de interpretación y traducción a la luz de factores que influyen en la labor de mediación lingüística, como el componente ideoló gico o cultural.

\section{Referencia}

KöLBL, Julia, OrLovA, Iryna y Wolf, Michaela (eds.) (2020): ¿Pasarán? Kommunikation im Spanischen Bürgerkrieg. Interacting in the Spanish Civil War. Viena: new academic press.

- New Approaches to Translation, Conflict and Memory. Narratives of the Spanish Civil War and the Dictatorship

Autoras: Lucía Pintado Gutiérrez y Alicia Castillo Villanueva (eds.) 
554 Editorial: Palgrave Macmillan

Año: 2019

Páginas: $234 \mathrm{pp}$.

Este volumen reúne trabajos que versan sobre traducción, conflicto y memoria histórica. Pone el foco en textos de ficción, informes de guerra y en las producciones audiovisuales sobre la Guerra Civil española y la dictadura. Estudia, además, la recepción y eficacia de las traducciones. De esta manera, la colección busca explorar la importancia del papel que desempeña la actividad traductora en la transmisión de un pasado cuyo eco sigue presente en los debates actuales sobre memoria histórica.

\section{Referencia}

Pintado Gutiérrez, Lucía, Castillo Villanueva, Alicia (eds.) (2019): New Approaches to Translation, Conflict and Memory. Narratives of the Spanish Civil War and the Dictatorship. Londres: Palgrave Macmillan.

- Translating in Town: Local Translation Policies During the European 19th Century

Autores: Lieven D'hulst y Kaisa Koskinen (eds.) Editorial: Bloomsbury Academic

Año: 2020

Páginas: $240 \mathrm{pp}$.

Los capítulos de este libro versan sobre la actividad traductora que se desarrolló en las comunidades multilingües europeas a lo largo del siglo XIX. El volumen abarca el período comprendido desde 1785 hasta 1914 y viaja por ciudades como Barcelona, Milán y Viena. El libro explora los conflictos y el diálogo que se produjo entre el monolingüismo oficial y el multilingüismo derivado de las lenguas locales con el fin de poner de relieve los distintos puntos de vista sobre las técnicas de traducción oficiales y no oficiales que se dieron durante esta época.

\section{Referencia}

D'HULST Lieven y Koskinen Kaisa (eds.) (2020): Translating in Town: Local Translation Policies During the European 19th Century, Londres: Bloomsbury Academic.

\section{DIDÁCTICA DE LA TRADUCCIÓN}

- Researching Cognitive Processes of Translation

Autores: Defeng Li, Victoria Lei y Yuanjian He (eds.)

Editorial: Springer

Año: 2019

Páginas: $201 \mathrm{pp}$.

Este volumen abarca cuestiones relevantes relacionadas los procesos cognitivos que tienen lugar en traducción. Explora cuestiones teóricas y metodológicas a través de estudios de caso y examina sus implicaciones prácticas y pedagógicas con el fin de mejorar los métodos y diseños de investigación o permitir que los profesionales comprendan sus propios comportamientos de traducción.

\section{Referencia}

Li, Defeng, Victoria Lei y Yuanjian He (eds.) (2019): Researching Cognitive Processes of Translation, Nueva York: Springer.

- Nuevas tendencias en Traducción e Interpretación: Enseñar, aprender e investigar en la revolución digital

Autora: Silvia Martínez (ed.)

Editorial: Comares

Año: 2020

Páginas: 200 pp.

Este libro aborda los últimos avances en tecnologías aplicados a la enseñanza, el aprendizaje y la investigación en traducción audiovisual, así como a la creación de nuevos perfiles profesionales, la transcreación y la localización de videojuegos. 


\section{Referencia}

MartíneZ, Silvia (ed.) (2020): Nuevas tendencias en Traducción e Interpretación: Enseñar, aprender e investigar en la revolución digital, Granada: Comares.

\section{TRADUCCIÓN PROFESIONAL}

- Perfiles estratégicos de traductores e intérpretes en la transmisión de la información experta multingüe en la sociedad del conocimiento del siglo XXI

Autoras: Susana Álvarez y María Teresa Ortego (eds.)

Editorial: Comares

Año: 2020

Páginas: 192 pp.

En este volumen se recopilan contribuciones que exploran los nuevos perfiles de traductores e intérpretes que demanda el mercado. Además, se examinan los nuevos nichos profesionales que han surgido en el mundo de la traducción y que se encuentran relacionados con la localización de videojuegos, la posedición y la transcreación.

\section{Referencia}

Álvarez Álvarez, Susana y María Teresa Ortego ANTón (eds.) (2020): Perfiles estratégicos de traductores e intérpretes en la transmisión de la información experta multingüe en la sociedad del conocimiento del siglo XXI, Granada: Comares.

\section{- The Bloomsbury Companion to Language In- dustry Studies}

Autores: Erik Angelone, Maureen EhrensbergerDow y Gary Massey (eds.)

Editorial: Bloomsbury

Año: 2019

Páginas: $424 \mathrm{pp}$.

Esta obra ofrece una perspectiva global sobre los aspectos clave que conforman la industria del lenguaje. Entre estos aspectos se incluyen la traducción, la interpretación, la traducción automática, le gestión terminológica, la accesibilidad, etc.

\section{Referencia}

Angelone, Erik, et al. (2019): The Bloomsbury Companion to Language Industry Studies, Londres: Bloomsbury Academic.

- Abanicos: enfoques y propuestas para la traducción y la interpretación en la era global

Autores: Carlos Fortea Gil, Mirella Marotta Peramós y Antonio Roales Ruiz (eds.)

Editorial: Guillermo Escolar Editor

Año: 2020

Páginas: 192 pp.

Este libro recoge propuestas novedosas en los campos de la didáctica de la traducción, la traducción profesional, la interpretación, la traducción literaria y la teoría y la práctica de la traducción. Asimismo, se examinan las nuevas tecnologías como instrumentos que facilitan la labor de los profesionales en este ámbito.

\section{Referencia}

ForTea Gil, Carlos, Mirella Marotta Peramós y Antonio Roales Ruiz (eds.) (2020): Abanicos: enfoques y propuestas para la traducción y la interpretación en la era global, Madrid: Guillermo Escolar Editor SL.

\section{TRADUCCIÓN LITERARIA}

- Traducciones, adaptaciones y doble destinatario en literatura infantil y juvenil

Autora: Elvira Cámara Aguilera (ed.)

Editorial: Peter Lang Publishing Group

Año: 2019

Páginas: 420 pp.

Esta obra reúne trabajos de investigación sobre traducción de literatura infantil y juvenil. Se 
556 tratan aspectos como las adaptaciones y el doble destinatario. Asimismo, se estudian géneros como el álbum ilustrado, la poesía o las historias en formato audiovisual. También se incluyen proyectos innovadores que pueden aplicarse en las aulas.

\section{Referencia}

CÁmARA Aguilera, Elvira (ed.) (2019): Traducciones, adaptaciones $y$ doble destinatario en literatura infantil y juvenil, Nueva York: Peter Lang Publishing Group.

\section{- La traducción del cómic}

Autores: Francisco Rodríguez Rodríguez y Sergio España Pérez (eds.)

Editorial: ACyT Editores

Año: 2019

Páginas: $268 \mathrm{pp}$.

Esta obra recoge el monográfico de la revista Tebeosfera dedicado a la traducción del cómic, en el que se incluyen tanto trabajos de expertos en traductología como de traductores especializados en el ámbito. De esta forma, el volumen aporta una visión académica y profesional de esta especialidad.

\section{Referencia}

Rodríguez Rodríguez, Francisco, Sergio España Pérez (eds.) (2019): La traducción del cómic, Sevilla: ACyT Editores.

\section{- A Companion to Medieval Translation}

Autora: Jeanette Beer (ed.)

Editorial: Arc Humanities Press

Año: 2019

Páginas: 208 pp.

Esta obra ofrece una guía de la profusa actividad de traducción que se dio durante la Edad Media. Además, se abordan los problemas teóricos y pragmáticos a los que se enfrentan los traductores modernos de obras medievales, obligados a mediar entre el pasado y el presente.

\section{Referencia}

BeER, Jeanette (ed.) (2019): A Companion to Medieval Translation, Leeds: Arc Humanities Press.

- Facetas multiculturales en producción y traducción: metáforas, alegorías y otras imágenes

Autora: Carmen C. Castro Moreno (ed.)

Editorial: Comares

Año: 2020

Páginas: $432 \mathrm{pp}$.

Este libro recopila trabajos centrados en aspectos como la literatura fantástica, la identidad lingüística en los discursos, conceptos sociopragmáticos y cognitivos, y terminología interpretativa y filosófica.

\section{Referencia}

CASTRo Moreno, Carmen Cayetana (ed.) (2020): Facetas multiculturales en producción y traducción: metáforas, alegorías y otras imágenes, Granada: Comares.

- Entre escritura y oralidad: literaturas y culturas en traducción e interpretación

Autores: Alessandro Ghignoli y Daniela Zizi (eds.)

Editorial: Comares

Año: 2019

Páginas: $152 \mathrm{pp}$.

Esta publicación reúne trabajos que pretenden acercarse al binomio oralidad y escritura que se da en el ámbito de la traducción y la interpretación desde una perspectiva literaria y cultural.

\section{Referencia}

GHIGNoli, Alessandro y Daniela Zizi (eds.) (2019): Entre escritura y oralidad: literaturas y culturas en traducción e interpretación, Granada: Comares. 


\section{- Traducir la traducción}

Autor: José Francisco Ruiz Casanova

Editorial: Cátedra

Año: 2020

Páginas: $240 \mathrm{pp}$.

Este volumen reúne reflexiones sobre el mundo académico y profesional de la traducción literaria con el fin de difuminar la distancia entre la reflexión teórica y la práctica traductora.

\section{Referencia}

RuIz Casanova, José Francisco (2020): Traducir la traducción, Madrid: Cátedra.

\section{TRADUCCIÓN DE POESÍA Y MÚSICA}

- Sociologies of Poetry Translation: Emerging Perspectives

Autor: Jacob Blakesley (ed.)

Editorial: Bloomsbury

Año: 2019

Páginas: $280 \mathrm{pp}$.

Este libro explora la rica variedad de aproximaciones que existen en torno a la traducción de poesía y que están surgiendo en la actualidad.

\section{Referencia}

Blakesley, Jacob (ed.) (2019): Sociologies of Poetry Translation: Emerging Perspectives, Londres: Bloomsbury Academic.

\section{- Music and Translation: New Mediations in the Digital Age}

Autora: Lucile Desblache

Editorial: Palgrave Macmillan

Año: 2019

Páginas: $407 \mathrm{pp}$.

Este libro explora de qué manera las traducciones moldean los significados musicales y la percepción de la música a través de las cultu- ras. Además, busca explicar cómo la actividad traductora impulsa el intercambio y la difusión cultural.

\section{Referencia}

Desblache, Lucile (2019): Music and Translation: New Mediations in the Digital Age, Londres: Palgrave Macmillan.

\section{TRADUCCIÓN AUDIOVISUAL}

\section{- Innovation in Audio Description Research}

Autoras: Sabine Braun y Kim Starr (eds.)

Editorial: Routledge

Año: 2020

Páginas: 214 pp.

Este volumen abarca los últimos avances en audiodescripción. Los trabajos que se incluyen discuten conceptos clave relacionados con los nuevos desarrollos y su aplicación. A su vez, presta atención a la innovación metodológica y realiza un análisis multidimensional de la cuestión lingüística y la experiencia del usuario.

\section{Referencia}

BRAUN, Sabine y Kim STARR (eds.) (2020): Innovation in Audio Description Research, Londres: Routledge.

\section{- Subtitling: Concepts and Practices}

Autores: Jorge Díaz Cintas y Aline Remael Editorial: Routledge

Año: 2020

Páginas: $292 \mathrm{pp}$.

Esta obra refleja los avances en la práctica y la investigación en subtitulación. Proporciona los conceptos básicos que permitirán a los usuarios familiarizarse con las características técnicas, lingüísticas y culturales de esta práctica. Además, se ofrecen estrategias de subtitulación y se analizan las tecnologías de traducción más avanzadas y su repercusión en la profesión. 
Referencia

Díaz Cintas, Jorge y Aline Remael (2020): Subtitling: Concepts and Practices, Londres: Routledge.

\section{TRADUCCIÓN Y MULTIMODALIDAD}

\section{- Translation and Multimodality: Beyond Words}

Autores: Mónica Boria et al. (eds.)

Editorial: Routledge

Año: 2019

Páginas: $224 \mathrm{pp}$.

Este volumen pone de manifiesto la necesidad de redefinir y reconfigurar la traducción en contextos multimodales.

\section{Referencia}

BorIA, Mónica et al. (eds.) (2019): Translation and Multimodality: Beyond Words, Londres: Routledge.

\section{- Translation and Translanguaging}

Autores: Mike Baynham y Tong King Lee Editorial: Routledge

Año: 2019

Páginas: 208 pp.

Esta obra considera el translenguaje y la traducción en conjunto a través del estudio de las lenguas, las variedades lingüísticas, los registros y los discursos en una amplia gama de contextos; por ejemplo, los entornos multilingües que implican la interpretación comunitaria y la mediación cultural, los deportes, etc. De esta manera, demuestra que las perspectivas de la traducción pueden enriquecer la comprensión del translenguaje y señala de qué manera puede el translenguaje ofrecer una explicación de la actividad traductora.

\section{Referencia}

Baynham, Mike y Tong King Lee (2019): Translation and Translanguaging, Londres: Routledge.

- Translating across Sensory and Linguistic Borders: Intersemiotic Journeys between Media

Autoras: Madeleine Campbell y Ricarda Vidal (eds.)

Editorial: Palgrave Macmillan

Año: 2019

Páginas: $433 \mathrm{pp}$.

Este libro analiza la traducción intersemiótica; por ejemplo, examina de qué manera puede un poema puede expresarse en forma de danza; un cuento como una experiencia olfativa o una película como una pintura. Así, pretende subrayar la naturaleza multimodal de la percepción y la expresión.

\section{Referencia}

CAmpbell, Madeleine y Ricarda Vidal (eds.) (2019): Translating across Sensory and Linguistic Borders: Intersemiotic Journeys between Media, Cham: Palgrave Macmillan.

- A (Bio)Semiotic Theory of Translation: The Emergence of Social-Cultural Reality

Autor: Kobus Marais

Editorial: Routledge

Año: 2020

Páginas: $218 \mathrm{pp}$.

Este volumen propone una teoría semiótica que no se limita a la traducción interlingüística, sino que comprende la traducción en todas sus modalidades.

\section{Referencia}

Marais, Kobus (2020): A (Bio)Semiotic Theory of Translation: The Emergence of Social-Cultural Reality, Londres: Routledge. 
TRADUCCIÓN DE TEXTOS CIENTÍFICOS Y TÉCNICOS

- Traducción, interpretación y ciencia: textos, contextos y tendencias contemporáneas

Autores: José María Castellano y Aurora Ruiz

Editorial: Comares

Año: 2019

Páginas: 224 pp.

Este libro trata la actividad traductora e interpretativa en varios ámbitos del saber especializado.

\section{Referencia}

Castellano Martínez, José María y Aurora Ruiz Mezcua (2019): Traducción, interpretación y ciencia: textos, contextos y tendencias contemporáneas, Granada: Comares.

- Retos de la traducción científico-técnica profesional: teoría, metodología y recursos

Autoras: Beatriz Sánchez Cárdenas y Clara Inés López Rodríguez

Editorial: Comares

Año: 2020

Páginas: $240 \mathrm{pp}$.

Este volumen repasa las bases teóricas que todo traductor científico debe dominar y presenta las herramientas lingüísticas e informáticas que pueden facilitar su labor. Desde una perspectiva transversal, se examina el proceso de la traducción científica, su contexto profesional y sus principales dificultades teóricas y prácticas.

\section{Referencia}

SÁnchez Cárdenas, Beatriz y Clara Inés López Rodríguez (2020): Retos de la traducción científico-técnica profesional: teoría, metodología y recursos, Granada: Comares.
- The Sociolinguistics of Survey Translation

Autoras: Yuling Pan, Mandy Sha y Hyunjoo Park Editorial: Routledge

Año: 2019

Páginas: $182 \mathrm{pp}$.

Este libro aborda varios temas entre los que se incluyen la relación entre las reglas lingüísticas, las normas culturales y las prácticas sociales y su repercusión en la traducción de encuestas. De esta manera, se pretende demostrar que la sociolingüística puede ser un marco útil para abordar los problemas que presenta este tipo de traducción $\mathrm{y}$, además, se proporcionan herramientas prácticas y útiles para la evaluación de la calidad de estos textos.

\section{Referencia}

Pan, Yuling, Mandy Sha y Hyunjoo Park (2019): The Sociolinguistics of Survey Translation, Londres: Routledge.

\section{TRADUCCIÓN PERIODÍSTICA}

- Journalism and Translation in the Era of Convergence

Autores: Lucile Davier y Kyle Conway (eds.)

Editorial: John Benjamins

Año: 2019

Páginas: $211 \mathrm{pp}$.

Este volumen investiga los diferentes modos en que distintas plataformas convergen y determinan la forma en que los periodistas redactan los textos, así como el papel que desempeñan en un mundo multilingüe y globalizado.

\section{Referencia}

DAVIER, Lucile y Kyle Conway (eds.) (2019): Journalism and Translation in the Era of Convergence, Ámsterdam: John Benjamins Publishing Company. 


\section{TRADUCCIÓN AUTOMÁTICA Y POSEDICIÓN}

- Traducción automática: conceptos clave, procesos de evaluación y técnicas de posedición

Autoras: María del Mar Sánchez Ramos y Celia Rico Pérez

Editorial: Comares

Año: 2020

Páginas: 128 pp.

Este libro estudia los cambios que han supuesto la traducción automática y la posedición para la actividad traductora. Se trata la historia de esta modalidad, se examina la clasificación de los diferentes sistemas de traducción automática y se profundiza en cuestiones de evaluación, lenguajes controlados y tareas de preedición y posedición.

\section{Referencia}

SÁnchez Ramos, María del Mar y Celia Rico Pérez (2020): Traducción automática: conceptos clave, procesos de evaluación y técnicas de posedición, Granada: Comares.

\section{- Translation Revision and Post-editing: Indus-} try Practices and Cognitive Processes

Autores: Maarit Koponen et al. (eds.)

Editorial: Routledge

Año: 2020

Páginas: 294 pp.

Esta obra recopila investigaciones recientes en posedición y revisión de traducciones en los departamentos de traducción gubernamentales y corporativos, las agencias de traducción y en el sector editorial, entre otros.

\section{Referencia}

Koponen, Maarit et al. (eds.) (2020): Translation Revision and Post-editing: Industry Practices and Cognitive Processes, Londres: Routledge.
- Using Computers in the Translation of Literary Style: Challenges and Opportunities

Autor: Roy Youdale

Editorial: Routledge

Año: 2021

Páginas: $258 \mathrm{pp}$.

Este volumen ofrece un enfoque interdisciplinar para el análisis y la traducción del estilo literario, ya que inserta la traducción literaria en el marco de la traducción asistida por ordenador.

\section{Referencia}

YoudALE, Roy (2021): Using Computers in the Translation of Literary Style: Challenges and Opportunities, Londres: Routledge.

\section{- A Project-Based Approach to Translation Tech- nology}

Autora: Rosemary Mitchell-Schuitevoerder

Editorial: Routledge

Año: 2020

Páginas: 200 pp.

Este volumen ofrece una experiencia de traducción en tiempo real que incluye el estudio de plataformas de traducción, los sistemas de gestión y el trabajo en equipo. Se identifican los elementos básicos de las herramientas del entorno de traducción y los métodos de trabajo colaborativo. Además, se repasan conceptos como memoria de traducción y base de datos terminológicas. Asimismo, se revisa la traducción automática y se analizan cuestiones como la calidad, la ética digital y los sistemas de gestión de la traducción basados en la web. De este modo, se pretende cubrir los pasos del flujo de trabajo de proyectos de traducción.

\section{Referencia}

Mitchell-Schuitevoerder, Rosemary (2020): A Project-Based Approach to Translation Technology, Londres: Routledge. 
TRADUCCIÓN ACTIVISTA

- Translating the Crisis Politics and Culture in Spain after the $15 \mathrm{M}$

Autor: Fruela Fernández

Editorial: Routledge

Año: 2020

Páginas: $180 \mathrm{pp}$.

Esta obra estudia las prácticas de traducción que dieron forma al movimiento del 15M. La monografía ofrece un estudio en profundidad del papel que desempeña la traducción en la renovación del lenguaje activista, el desarrollo de plataformas políticas y la creación de nuevos referentes sociales, al tiempo que presenta una perspectiva crítica sobre sus limitaciones y carencias.

\section{Referencia}

FERnÁNDEZ, Fruela (2020): Translating the Crisis Politics and Culture in Spain after the 15M, Londres: Routledge.

\section{- Traduire Les Voix de La Nature / Translating the Voices of Nature}

Autores: Kristiina Taivalkoski y Bruno Poncharal (eds.)

Editorial: Bloomsbury

Año: 2019

Páginas: $230 \mathrm{pp}$.

Esta obra examina cómo se realiza el trasvase de las voces de la fauna, la flora, las fuerzas naturales y los diferentes ecosistemas de una lengua a otra. Se pone de manifiesto cómo estas voces pueden ser silenciadas, malinterpretadas o recreadas mediante la traducción.

\section{Referencia}

Kristinna, Taivalkoski-Shilov y Bruno Poncharal (eds.) (2020): Traduire Les Voix de La Nature/Translating the Voices of Nature, Quebec: Éditions Québécoises de l'Euvre.

\section{TRADUCCIÓN Y CONFLICTO}

- The Dark Side of Translation

Autor: Federico Italiano (ed.)

Editorial: Routledge

Año: 2020

Páginas: $196 \mathrm{pp}$.

Esta obra recuerda que la traducción puede funcionar como un instrumento que oscurece y difumina el mensaje original. Así, examina las situaciones en las que esta práctica constituye un espacio de conflicto. Para ello, reúne trabajos de especialistas de diversas disciplinas.

\section{Referencia}

ITALIANo, Federico (ed.) (2020): The Dark Side of Translation, Londres: Routledge.

\section{- Intercultural Crisis Communication: Transla-} tion, Interpreting and Languages in Local Crises

Autores: Federico M. Federici y Christophe Declercq (eds.)

Editorial: Bloomsbury

Año: 2019

Páginas: 280 pp.

Este volumen explora el papel de la traducción, la interpretación y la mediación en contextos de crisis mediante el estudio de casos contemporáneos que incluyen el desplazamiento sirio, la crisis de los refugiados en Croacia e Italia, el terrorismo internacional, etc.

\section{Referencia}

Federici, Federico M. y Christophe Declercq (eds.) (2019): Intercultural Crisis Communication: Translation, Interpreting and Languages in Local Crises, Londres: Bloomsbury. 


\section{TRADUCCIÓN DE LENGUAS MINORITARIAS}

- Translating the Literatures of Small European Nations

Autores: Rajendra Chitnis et al.

Editorial: Liverpool University Press

Año: 2019

Páginas: $304 \mathrm{pp}$.

Este libro estudia de qué manera las literaturas europeas escritas en lenguas de la periferia llegan al resto del mundo a través de la traducción. Para ello, se emplea un enfoque interdisciplinario que incluye aproximaciones literarias, históricas, sociológicas y de género. De esta manera, se pretende mostrar las estrategias, a menudo pioneras e innovadoras, que se dan cuando estas literaturas se enfrentan a las desigualdades que supone la globalización.

\section{Referencia}

ChITNIs, Rajendra, et al. (2019): Translating the Literatures of Small European Nations, Liverpool: Liverpool University Press.

\section{- Translation in Diasporic Literatures}

Autor: Guanglin Wang

Editorial: Palgrave

Año: 2019

Páginas: $144 \mathrm{pp}$.

Esta obra examina el fenómeno de la traducción en las literaturas de la diáspora, especialmente en China y Australia.

\section{Referencia}

WANG, Guanglin (2019): Translation in Diasporic Literatures, Londres: Palgrave Pivot.
TRADUCCIÓN, GÉNERO Y POSCOLONIALISMO

- Hybrid Englishes and the Challenges of and for Translation: Identity, Mobility and Language Change

Autoras: Karen Bennett y Rita Queiroz de Barros (eds.)

Editorial: Routledge

Año: 2019

Páginas: $238 \mathrm{pp}$.

Este volumen problematiza la práctica de la traducción en un mundo interconectado en el que el inglés, a pesar de su estatus hegemónico, ya no puede considerarse una entidad unificada y coherente, sino más bien un recurso móvil sujeto a diversos tipos de hibridación.

\section{Referencia}

BenNETT, Karen y Rita QueIroz de BARRos (eds.) (2019): Hybrid Englishes and the Challenges of and for Translation: Identity, Mobility and Language Change, Londres: Routledge.

- Queer Theory and Translation Studies: Language, Politics, Desire

Autor: Brian J. Baer

Editorial: Routledge

Año: 2020

Páginas: 238 pp.

Esta obra explora la relevancia de la teoría queer en el ámbito de la Traductología a través de una serie de estudios de caso que ejemplifican cuestiones éticas clave. Además, estudia la labor de los traductores queer y la recepción de textos queer.

\section{Referencia}

BAER, Brian J. (2020): Queer Theory and Translation Studies: Language, Politics, Desire, Londres: Routledge. 
- Transgender, Translation, Translingual Address

Autor: Douglas Robinson

Editorial: Bloomsbury

Año: 2019

Páginas: $288 \mathrm{pp}$.

El autor trata de entender los diálogos «traslativos» o «translingüísticos» que se dan entre personas cisgénero y transgénero. Para ello, se basa en un amplio abanico de estudiosos LGBT, filósofos, sociólogos, sexólogos y voces literarias.

\section{Referencia}

RoBinson, Douglas (2019): Transgender, Translation, Translingual Address. Londres: Bloomsbury.

- En otras palabras: género, traducción y relaciones de poder

Autoras: María Dolores Martos, Marina Sanfilippo y Mariángel Soláns

Editorial: UNED

Año: 2020

Páginas: 279 pp.

Este libro incorpora en el proceso de traducción, tradicionalmente considerado anónimo y neutro, nociones como ideología, identidad y estructuras de poder. Asimismo, aporta contribuciones que abordan la actividad traductora desde una perspectiva feminista y de género.

\section{Referencia}

Martos Pérez, María Dolores, Marina Sanfilippo y Mariángel Soláns García (2020): En otras palabras: género, traducción y relaciones de poder, Madrid: UNED - Universidad Nacional de Educación a Distancia.

\section{- Feminismo(s) y/en traducción}

Autor: José Ruiz Santaemilia (ed.)

Editorial: Comares

Año: 2020

Páginas: $172 \mathrm{pp}$.
Este volumen reúne artículos que exploran la conexión entre feminismos(s) y traducción.

\section{Referencia}

Santaemilia Ruiz, José (coord.) (2020): Feminismo(s) y/en traducción, Granada: Comares.

- Traducción y violencia simbólica: post-traducciones del cuerpo femenino en los medios de comunicación

Autora: Irene Rodríguez Arcos

Editorial: Comares

Año: 2019

Páginas: 144 pp.

Este libro estudia la dimensión ética de la traducción en el entorno mediático para poner de manifiesto los discursos que representan las imágenes-texto, que en numerosas ocasiones constituyen narrativas que contienen violencia simbólica hacia la mujer.

\section{Referencia}

RoDríGUEZ ARcos, Irene (2019): Traducción y violencia simbólica: post-traducciones del cuerpo femenino en los medios de comunicación, Granada: Comares.

\section{- Translation: An advanced resource book for} students

Autores: Basil Hatim y Jeremy Munday

Editorial: Routledge

Año: 2019

Páginas: $394 \mathrm{pp}$.

Esta obra aborda la teoría y la práctica de la traducción desde diversas aproximaciones lingüísticas y culturales. Se incluye un estudio de la traducción a través de aspectos como la semántica, la lingüística funcional, la lingüística cognitiva y los enfoques de corpus, el análisis del discurso, los estudios de género y el poscolonialismo. Además, se presenta material procedente de diversas fuentes, géneros y tipos de texto. 


\section{Referencia}

Hatim, Basil y Jeremy Munday (2019): Translation: An advanced resource book for students, Londres: Routledge.

\section{ESTUDIOS POR ÁREAS GEOGRÁFICAS}

\section{- Translation in the Arab World: The Abbasid Golden Age}

Autor: Adnan K. Abdulla

Editorial: Routledge

Año: 2020

Páginas: $164 \mathrm{pp}$.

En esta obra se investigan los conflictos culturales y políticos originados por la actividad traductora que se dio en el estado abasí desde una perspectiva sociológica.

\section{Referencia}

Abdulla, Adnan K. (2020): Translation in the Arab World: The Abbasid Golden Age, Londres: Routledge.

\section{- Translation and Literature in East Asia: Bet- ween Visibility and Invisibility}

Autoras: Jieun Kiaer, Jennifer Guest y Xiaofan Amy Li

Editorial: Routledge

Año: 2019

Páginas: $128 \mathrm{pp}$.

Esta obra explora distintos aspectos que se dan en la traducción entre el chino, el japonés y el coreano, así como de estas lenguas hacia idiomas europeos. De esta forma, compara las culturas de la traducción presentes en Asia Oriental y sus complejas interrelaciones. Asimismo, las autoras reafirman la necesidad de un cambio de paradigma en la teoría de la traducción que tenga en consideración otras lenguas aparte de las europeas.

\section{Referencia}

Kiaer, Jieun, Jennifer Guest y Amy Li Xiaofan (2019): Translation and Literature in East Asia: Between Visibility and Invisibility, Londres: Routledge.

\section{TRADUCCIÓN Y MODERNISMO}

\section{- Modernism and Non-Translation}

Autores: Jason Harding y John Nash

Editorial: Oxford University Press

Año: 2019

Páginas: $256 \mathrm{pp}$.

Este libro explora la incorporación de fragmentos de textos no traducidos en la escritura modernista. De esta manera, examina la no traducción en la ficción modernista, la poesía y otras formas de escritura, con un enfoque principalmente europeo.

\section{Referencia}

HARDING, Jason y John Nash (2019): Modernism and Non-Translation, Oxford: Oxford University Press.

\section{- The Classics in Modernist Translation}

Autoras: Miranda Hickman y Lynn Kozak (eds.) Editorial: Bloomsbury

Año: 2019

Páginas: $288 \mathrm{pp}$.

Este volumen se centra en el compromiso de principios del siglo xx con la literatura de la antigüedad grecorromana, aspecto que dio forma significativa a la obra del modernismo literario anglófono. Los ensayos se centran en la «traducción», un concepto que los propios modernistas utilizaron para relacionarse con los clásicos y para denotar lo que los estudios de recepción contemporáneos denominarían «adaptación», «refiguración»e «intervención».

\section{Referencia}

Hickman, Miranda y Lynn Kozak (eds.) (2019): The Classics in Modernist Translation, Londres: Bloomsbury Publishing. 